\title{
Mitigating the effects of the climate crisis through health policy
}

\author{
Ashley Farrell ${ }^{*}$ \\ Department of Community Health \& Humanities, Memorial University, St. John's, NL, Canada \\ ${ }^{\star}$ Author for correspondence (amsfarrell.mun.ca)
}

\begin{abstract}
: mitigate the effects of the climate crisis and improve healthcare in the country. $\mathrm{CO}_{2}$ emissions in the healthcare sector.

This report synthesizes current research on how the climate crisis is affecting health in Canada. It references both evidence-based and predictive literature by centering the voices of healthcare providers, environmental academics, social scientists, and media outlets to help establish a well-rounded view of the climate crisis and climate action by way of health policy. Suggestions for government action are given, according to the research.
\end{abstract}

In Canada, the climate crisis has had profound impacts on health, including increased health problems as well as decreased access to healthcare services. Without mitigation, the climate crisis is expected to exacerbate an abundance of negative health outcomes and health system disruptions in Canada, including: food, water, and shelter insecurity; increased health problems caused by severe weather; and forced displacement from geographically vulnerable areas. Governmental action could be taken to

This report synthesizes current literature on how the climate crisis is affecting health in Canada. It also recommends 3 actions that can be taken to mitigate the effects of the climate crisis and improve the country's health. Actions include: conducting climate change and health vulnerability assessments (CCHVAs), enhancing support for climate action research, and reducing

\section{Background: The climate crisis in Canada}

The climate crisis is defined as a severe change in global climate patterns. Currently, the earth's climate system has changed almost beyond repair [1]. If not mitigated, it is predicted that by 2060, all areas of Canada will experience increased mean temperatures, leading to a decrease in public health and access to healthcare services [1].

\section{The climate crisis is affecting public health}

Studies across Canada indicate that common concerns around the climate crisis include air and water quality as well as food access $[2,3]$. These concerns are well founded as additional research shows that poor air quality has contributed to respiratory diseases [such as asthma] and food-borne diseases [such as Salmonella and Staphylococcus] [1,2]. Air quality, clean water, and food access are also among the major health risks associated with the climate crisis [4].
With these general concerns in mind, specific social groups in Canada are at higher risk of poor health due to the climate crisis given their economic status, geographic location, and pre-existing health care inequities $[1,5,6]$. For example, poorer populations are susceptible to higher burdens of disease as a result of their social and political environments [6]. Moreover, people of low socioeconomic status often do not have the financial resources for medical interventions or prevention services such as prescription medications and good nutrition [7]. Likewise, populations on the coasts of the country are more vulnerable to flooding as sea level increases $[8,9]$. Besides, health inequity is particularly pronounced among Indigenous Canadians [1]. For this population, changing temperatures can impact the distribution and availability of, for example, animal populations - which are important in Indigenous subsistence hunting and are a foundational food resource [1].

\section{The climate crisis is diminishing access to healthcare}

The climate crisis makes access to affordable, high-quality care challenging by exacerbating health needs and healthcare provider shortages [10]. This is seen for example in how non-communicable diseases (i.e. cardiovascular disease, chronic respiratory disease, and diabetes) account for $71 \%$ of global deaths, and the causes for those diseases are made worse by environmental factors $[4,6,11]$. For example, while
OPEN

(O) by/4.0/ https://doi.org/10.29173/hsi287

Received 25 February 2020 Accepted 05 June 2020 
several factors can trigger a cardiovascular event, exposure to air pollutants - such as byproducts from the burning of fossil fuels - can penetrate past our body's natural defenses and into our respiratory and circulatory system, damaging our lungs, heart and brain [11]. Similarly, prolonged elevated temperatures (i.e., due to global warming) increase the vectoral capacity of disease and the frequency of food-borne illness $[5,6]$, as evidenced in the Canadian North and Indigenous communities $[3,12]$.

With increases in the frequency of chronic health problems, more people require ongoing healthcare services. However, research has shown that Canada already has a shortage and an unbalanced distribution of healthcare workers across provinces. In Atlantic Canada, for example, residents wait an average of four years for a family doctor, and wait times for health services are the highest in the country $[5,6$, 13]. The climate crisis can be expected to make this worse as more people develop illnesses that are linked with, or exacerbated by, environmental factors.

\section{Possible policy options and their implications}

Climate change predictions can aid in developing early warning and response systems for at-risk areas and can provide critical time to put proactive measures in place to reduce the frequency of climate-sensitive health outcomes [14]. Accordingly, recommendations for Canadian governments are suggested in this section to mitigate some of the impacts of the climate crisis.

\section{Recommendation 1: Conduct climate change and health vulnerability assessments (CCHVAs)}

A CCHVA is an evidence-based assessment of past, present, and future health impacts of climate change in a given geographic area [15]. CCHVAs are designed to better understand vulnerability - or the degree to which populations are susceptible to the effects of climate change - and they can be conducted in a relatively short time frame (approximately 1 to 3 months) with limited resources. The process in which CCHVAs are conducted includes 5 steps: framing the assessment relative to the geographic area; describing the current condition of health risks, vulnerabilities and adaptive capacity; projecting future climate and health risks; developing programs or policies to manage those health risks; and, establishing a process for monitoring and evaluating climate and health risks [16]. Each step of the process involves a CCHVA team (usually public health authority members) collaborating with local climate organizations and municipal stakeholders to generate context-specific data for the area being assessed. While the CCHVA team aggregates data on historical climate conditions and predicts future climate vulnerability through statistical modeling, interviews and focus groups are often used in order to increase understanding of local climate impacts and associated mitigation and adaption actions [17]. CCHVAs are useful to mitigating the climate crisis because they allow health authorities to better identify which people and places are most vulnerable to the health effects resulting from the climate crisis [18]. Upon identifying these jurisdictions, targeted public health interventions can be implemented. CCHVAs also consider how existing health inequities can be exacerbated by a changing climate and provide guidance on how to direct budgets and personnel to reduce both vulnerabilities and inequities over time [15]. Framing CCHVAs in relation to health equity can lend political credibility to the assessment method given the promotion of health equity is a broadly articulated goal of public health practice in Canada [5].

The success of CCHVA's can be seen in Ontario, where CCHVAs helped pave the way for the development of provincial guidance documents to support the province's Public Health Units in conducting their own assessments [15, 17]. The application of CCHVAs in Ontario prompted policy development through the formation of a framework that enables the identification of community vulnerabilities as well as mitigation and adaptation strategies [17]. As a result, they are able to raise awareness about the health hazards of climate change and reduce public health vulnerability $[17,19]$. In the Muskoka region, for example, the Muskoka Watershed Council had completed vulnerability assessments that identified projected environmental risks from climate change $[17,20]$. These included increased severe weather events that would lead to infrastructure damage and flooding [20]. The vulnerability assessment allowed the Simcoe-Muskoka District Health Unit to explore and evaluate climate change mitigation and adaptation actions, including the strengthening and broadening of the existing lake level monitoring as well as establishing the position of Director of Climate Adaptation within the District Municipality of Muskoka government [20]. Because of CCHVA application, Ontario Public Health Units, such as that of Muskoka, are now better positioned to meet public health standards mandating the communication of climate change health risks with the public. A similar approach could be taken in other parts of the country.

Despite the benefits of CCHVAs, public health decision-makers may decide not to conduct such assessments due to lack of human resources, lack of technical capacity, limited funds, or the absence of political will to initiate and drive the assessment process. This may be the case when climate change mitigation is not identified as immediate or near-term priority, when there is climate change denial within public health leadership, or when climate change is not understood as a public health issue [15]. Efforts to increase awareness of how the climate crisis is a public health issue will be needed in order to incorporate CCHVAs into governmental practice. Such efforts may include supporting the creation of partnerships between public health officials and provincial governments - partnerships that can ensure climate action continues - as is evidenced in Ontario's application of the assessment [17, 19]. Similarly, raising awareness of the assessments cost-effectiveness could increase their use. The National Roundtable for the Economy and Environment estimates that between 
2010 and 2100, the cumulative costs of premature mortality risk attributable to only heat and air quality impacts resulting from climate change will be $\$ 65-\$ 96$ billion CAD for Toronto, \$52-\$77 billion for Montreal, and \$36-\$48 billion for Vancouver [21]. CCHVAs could enable the analysis of cost-effectiveness of identified interventions wherever possible.

\section{Recommendation 2: Enhance support for climate-action research}

To provide support for climate-action research, two actions are suggested: for climate action to be prioritized by healthcare funding agencies and for governments to capitalize on environmental data $[4,6]$. Firstly, investment in research to understand the health risks of climate change in local populations would allow for a more accurate measurement of the disease-control measures currently in place across Canada [6]. Moreover, opportunities exist to capitalize on the environmental data produced [22]. These opportunities include the development of early warning and response systems that can provide critical time to deploy proactive measures to reduce the number of cases of climate-sensitive health outcomes [1, 22]. Such systems include, for example, warning the population of extreme heat events and ensuring those most vulnerable to the event (i.e. elderly) have access to safety measures (e.g. air conditioning) [22]. In order to develop these response systems, the information generated from climate-action research can be combined with a cost-benefit analysis or other decision support tool to inform priority setting by policy makers as the climate crisis progresses in Canada [23].

Supporting climate action research is useful for mitigating the climate crisis because current policies and measures for the management of climate-sensitive health outcomes were not developed in light of the rate of climate-change. This means that they need modification to be effective over coming decades [1]. By investing in research that measures the accuracy of disease-control interventions, health effects can be better controlled, as population health needs change alongside the climate crisis' progression. In public health, evidence-based models can help achieve the social convergence required for a sustainable global economy whose principal objective is wellbeing for all [24].

While there are costs associated with funding climate-action research, mitigating the climate crisis through climate action research makes economic sense [21, 25]. By 2050, the climate crisis is predicted to cost Canada between $\$ 21$ and $\$ 43$ billion per year [21]. This total is derived from flooding damages to the coasts ( $\$ 1$ billion to $\$ 8$ billion/year) and poor air quality resulting from higher temperatures. Notably, both events are predicted to cost millions of dollars to the health care systems of Canada's 4 major cities - Toronto, Montreal, Vancouver, and Calgary [21]. The economic benefit of climate action will not only increase public health, but will aid institutions over the longer-term by developing preventative and adaptation strategies, rather than fixing health problems as they occur [2].
The largest barriers to enhancing climate-action support is the lack of knowledge surrounding the economic benefit of climate action [21,22] and how the climate crisis is a public health problem $[1,2]$. Health researchers recommend re-framing climate change as a public health issue, by way of increasing research in the field [2]. Benefits of increasing climate action research are shown in a study of climate crisis perceptions: when climate change was introduced as a health problem with mitigation-related policy options, $83 \%$ of respondents saw climate-action centered health policy as a plausible option to mitigate the climate crisis [26]. Increased interest in climate action was also present when an effect of the climate crisis [air pollution] was reframed to government and policy officials through economic cost-benefit analysis for reducing local air pollution and addressing air quality through climate policies [27]. Re-framing the climate crisis as a public health issue could be expanded with more research that relates the climate crisis to public health.

\section{Recommendation 3: Create policies to reduce $\mathrm{CO}_{2}$ emissions in the healthcare sector}

The health sector produces a disproportionate amount of carbon emissions - about $4 \%$ of the world's $\mathrm{CO}_{2}$ emissions come from the health sector [28]. A rapid transition to renewable energy would have direct health benefits now and would minimize health burdens in the future [6].

A step towards low-carbon living has health benefits that will improve quality of life by challenging diseases arising from affluent high-carbon societies - obesity, diabetes, and heart disease especially - and reducing the effects of air pollution [25]. For hospital buildings, this would imply improving building codes with a careful assessment of energy saving potentials (e.g. lighting and operation of energy intensive medical machinery and IT equipment). A switch to carbon efficient heating and cooling technologies as well as carbon efficient vehicles would further contribute to energy savings [29]. Health professionals would play an important role in advocating for policies that will incentivize this transition. Provincial governments would subsequently respond to health providers needs in order to implement policies concerned with $\mathrm{CO}_{2}$ reduction in workspaces like hospitals and clinics.

If we do everything we can now to reduce global greenhouse gas emissions and ensure we adapt to the future effects of climate change, the average estimated cost is $1 \%$ of the world gross domestic product (GDP) every year. However, if we do nothing, the effects of climate change could cost $5-20 \%$ of the world GDP every year [25]. With this in mind, the Lancet Countdown to 2030, a working group focusing on climate action, has identified the price of the health impacts of fossil fuels as an important economic incentive to accelerate progress on climate action and health [28]. This incentive can be seen, for example, in the International Monetary Fund (IMF) estimation of nationally appropriate energy prices. Proposed prices incorporate health impacts, could cut ambient air pollution deaths by approximately one third, and reduce 
gas emissions by more than $20 \%$ [30].

Upfront costs for renewable resources are a barrier to reducing $\mathrm{CO}_{2}$ emissions in the health sector $[19,21]$. Knowledge translation and provider advocacy for these products is needed in order to develop policies and actions surrounding $\mathrm{CO}_{2}$ reduction. Further, efforts to expand knowledge on how the climate crisis is a public health issue will be needed in order to incorporate $\mathrm{CO}_{2}$ reduction into the health sector's practices.

\section{Conclusion}

The climate crisis is negatively affecting public health levels and decreasing access to health services in Canada. Without mitigation, the climate crisis is expected to exacerbate an abundance of negative health outcomes and health system disruptions in the country. With that said, governmental action could be taken to mitigate the effects of the climate crisis and improve healthcare. Three actions to mitigate the effects of the climate crisis and improve the country's health were proposed in this article. The benefits of each action were discussed and included recognition of vulnerable groups, increased economic benefit in the long-term, increased awareness of the climate crisis, and decreased health burdens resulting from the changing climate. Barriers to actions were also discussed - they largely included upfront costs, lack of resources, and a lack of knowledge surrounding how the climate crisis is a public health issue.

Further research on how the climate crisis can be mitigated through health policy may include a comparative analysis of how the crisis is perceived and addressed pre and post CCHVA. This information is missing in the literature as the results of CCHVA's are presented in terms of recognition of health risks and the development of toolkits and systems - which may or may not be useful to mitigating climate crisis effects. Future research may also explore federal-level application of the suggested strategies and how Canada-wide climate crisis mitigation differs from provincial health policy action. Similarly, a comparative study could be completed between Canada's climate action strategies and those of other countries. This may be useful as developing countries are disproportionally affected by the climate crisis and we can learn from their actions should the crisis progress in Canada as predicted.

\section{References}

1. Ford, J., Berrang-Ford, L., King, M., \& Furgal, C. (2010). Vulnerability of Aboriginal health systems in Canada to climate change. Global Environmental Change, 20(2010), 668-680. Doi: 10.1016/j.gloenvcha.2010.05.003

2. Cardwell, F., \& Elliott, J. (2013). Making the links: do we connect climate change with health? A qualitative case study from Canada. BMC Public Health, 13(208). Retrieved from: http://www.biomedcentral.com/1471-2458/13/208

3. Tagalik, S. (2011) Arviat, Nunavit. p14-16. In Health Canada (Eds.), Communities Voices on Climate Change and Health Adaptation in Northern Canada: Summary Report of Health Canada's Climate Change and Health Adaptation Program for Northern First Nations and Inuit Communities (2008-2011). Retrieved from: http://www. climatetelling.info/uploads/2/5/6/1/25611440/final_summaryre- port_eng_sm.pdf

4. Haines, A. \& Ebi, K. (2019). The imperative for climate action to protect health. New England Journal of Medicine. 380(3), 263-73. Doi: 10.1056/NEJMra1807873 30650330

5. Poutianen, C., Berrang-Ford, L., Ford, J., \& Heymann, J. (2013). Civil society organizations and adaptation to the health effects of climate change in Canada. Elsevier Public Health, 27(2013), 403-409. Doi: 10.1016/j.puhe.2013.02.004

6. Salas, R. (2019). Climate change threatens the achievement of effective universal healthcare. BMJ, 366(5302), 1-7. Doi: 10.1136/ bmj.15302

7. Hallegatte S, et. al. (2016). Shock Waves: Managing the Impacts of Climate Change on Poverty. World Bank Group. Retrieved from: https://openknowledge.worldbank.org/bitstream/handle/10986/22787/9781464806735.pdf

8. Hess, J., Malilay, J., \& Parkinson, A. (2008). Climate change: The importance of place. American Journal of Prevention, 35(1), 468-78. Doi: 10.1016/j.amepre.2008.08.024

9. Lemmen, D. (2008). From impacts to adaptation: Canada in a changing climate 2007. Retrieved from: https://www.nrcan.gc.ca/ environment/resources/publications/impacts-adaptation/reports/ assessments/2008/10253

10. Bloom G., Katsuma, Y., Rao, KD., Makimoto, S., Yin, JDC., Leung, GM. (2019). Next steps towards universal health coverage call for global leadership. BMJ, 365(2107). Doi: 10.1136/bmj.12107 31126926

11. World Health Organization (WHO). (2019). How air pollution is destroying our health. Retrieved from: https://www.who.int/airpollution/news-and-events/how-air-pollution-is-destroying-our-health

12. Stephen, G. (2011). White River First Nation, Yukon. p. 1719. In Health Canada (Eds.), Communities Voices on Climate Change and Health Adaptation in Northern Canada: Summary Report of Health Canada's Climate Change and Health Adaptation Program for Northern First Nations and Inuit Communities (2008-2011). Retrieved from: http://www.climatetelling.info/uploads/2/5/6/1/25611440/final_summaryreport_eng_sm.pdf

13. Barua, B., Jacques, D., \& Collyer, A. (2018). Waiting your turn: Wait times for health care in Canada, 2018 Report. Fraser Institute. Retrieved from: https://www.fraserinstitute.org/sites/default/files/ waiting-your-turn-2018.pdf

14. Lowe, R., Stewart-Ibarra, A., Petrova, D., et al. (2017). Climate services for health: predicting the evolution of the 2016 dengue season in Machala, Ecuador. Lancet Planet Health, 1(4): e142-e151. Doi: $10.1016 / \mathrm{S} 2542-5196(17) 30064-5$

15. Buse, C. (2018). Why should public health agencies across Canada conduct climate change and health vulnerability assessments? Canadian Journal of Public Health, 2018(109) 782-785. Doi: 10.17269/ s41997-018-0118-6

16. World Health Organization (WHO). (2012). Protecting health from climate change: vulnerability and adaptation assessment. Retrieved from: https://apps.who.int/iris/handle/10665/104200

17. Levison, M., Butler, A., Rebellato, S., Armstrong, B., Whelan, M., \& Gardner, C. (2018). Development of a Climate Change Vulnerability Assessment Using a Public Health Lens to Determine Local Health Vulnerabilities: An Ontario Health Unit Experience. International Journal of Environmental Research and Public Health, 15(10), 2237. Doi: $10.3390 /$ ijerph 15102237

18. U.S. Climate Resiliance Toolkit. (2019). Assessing Health Vulnerability Assessments: A guide for health departments. Retrieved from: https://toolkit.climate.gov/tool/assessing-health-vulnerability-climate-change-guide-health-departments

19. Paterson, J., Yusa, A., Anderson, V., et al. (2016). Ontario climate change and health vulnerability and adaptation assessment guidelines. Toronto, ON: Ministry of Health and Long-Term Care. Retrieved from: http://www.health.gov.on.ca/en/common/ministry/ publications/reports/climate_change_toolkit/climate_change_ health_va_workbook.pdf

20. Sale, P., Lammers, R., Yan, N., Hutchinson, N., Trimble, K., Dinner, P., Hurrell, P., McDonnell, J., Young, S. (2016). Planning for Climate Change in Muskoka: A Report from the Muskoka Watershed Council. Muskoka Watershed Council: Muskoka, ON. Retrieved from: http://www.muskokawatershed.org/wp-content/uploads/ClimateChange_Muskoka-2016.pdf

21. National Roundtable for the Environment and Economy (NRTEE). (2011). Paying the Price: The economic impacts of climate change for Canada. Retrieved from: http://nrt-trn.ca/climate/climate-pros- 
perity/the-economic-impacts-of-climate-change-for-canada/payingthe-price

22. Ebi, K., Kovats, R., \& Menne, B. (2006). An approach for assessing human health vulnerability and public health interventions to adapt to climate change. Environmental Health Perspectives, 114(1), 19304. Doi: $10.1289 /$ ehp. 8430

23. Willows, R., Reynard, N., Meadowcroft, I., \& Connell, R. (2003).

Climate adaptation: Risk, uncertainty and decision-making. UKCIP Technical Report. Climate Impacts Program: Oxford, UK. Retrieved from: http://nora.nerc.ac.uk/id/eprint/2969/

24. Hanlon, P., \& Carlisle, S. (2008). Do we face a third revolution in human history? If so how will public health respond? Journal of Public Health, 30(1), 355-61. Doi: 10.1093/pubmed/fdn058

25. Costello, A., Lee, M., \& Oliveira, P. (2009). Managing the health effects of climate change. Lancet and University College London Institute for Global Health Commission. 373(9676), 1693-1733. Doi: 10.1016/S0140-6736(09)60935-1

26. Maibach, E., Nisbet, M., Baldwin, P., Akerlof, K., \& Diao, G. (2010) Reframing climate change as a public health issue: an exploratory study of public reactions. BMC Public Health, 10(299), Doi: 10.1186/1471-2458-10-299

27. Workman, A., Blashki, G., Bowen, K., Karoly, D., \& Wiseman, J. (2018). The Political Economy of Health Co-Benefits: Embedding Health in the Climate Change Agenda. International Journal of Environmental Research and Public Health. 15(4), 674. Doi: 10.3390/ ijerph15040674

28. Eckelman, M., Sherman, J., \& MacNeill, A. (2018). Life cycle environmental emissions and health damages from the Canadian healthcare system: An economic-environmental-epidemiological analysis. PLoS Medicine. 15(7), e1002623. Doi: 10.1371/journal. pmed.1002623

29. Pichler, P., Jaccard, I., Weisz, U., \& Weisz, H. (2019). International comparison of health care carbon footprints. Environmental Research Letters, 14(6), Doi: 10.1088/1748-9326/ab19e1

30. Coady, D., Parry, I., Sears, L., \& Shang, B. (2015). IMF Working Paper: How Large Are Global Energy Subsidies? Retrieved from: https://www.imf.org/external/pubs/ft/wp/2015/wp15105.pdf

(C) The Author(s) 